\title{
Samhällets olycksbarn, kreatörer eller Svenssons? Modsens framtid i backspegeln
} SUSANNE ALM \& ANDERS NILSSON

\begin{abstract}
Modsen var en ungdomskultur sompå 1960-talet skrämde och oroade vuxenvärlden. I denna artikel följer vi dem somi ungdomen kallade sig mods upp i vuxen ålder. Hur gick det för dem? Fanns det fog för de vuxnas oro?
\end{abstract}

Ungdomskulturer både skrämmer och fascinerar. De som framför allt skräms kan uttrycka oro för "vart samhället är på väg" och hur det ska bli när dagens ungdomar blir vuxna. Lättja, bristande ansvarskänsla och respekt för andra kan vara några av orosmomenten. Avvikande inställning till droger och sexualitet kan vara andra (Ohlsson \& Swärd 1994).

Bland dem som istället vill bejaka ungdomens alternativa uttrycksformer talas tvärtom om vikten av och naturligheten $\mathrm{i}$ att ungdomen gör uppror mot föräldragenerationen och mot samhället. Ibland finns en närmast idylliserande inställning till revolt

Susanne Alm, fil.dr. i sociologi, forskare vid Institutet för Framtidsstudier, Stockholm

Anders Nilsson, docent i kriminologi, forskare vid Institutet för Framtidsstudier, Stockholm och en stark tro på dess betydelse för vitalitet och kreativitet. Det finns också studier som pekat på att ungdomskulturer kan främja en kreativ yrkesverksamhet längre fram i livet (Brill 2006, Dannefjord \& Eriksson 2007).

Det tycks som ungdomskulturer lätt blir en projektionsyta för djupare värderingar hos den vuxna befolkningen, och att de reaktioner de väcker kanske ofta har en begränsad resonansbotten i vad kulturerna verkligen står för. För om ungdomskulturer alltså väcker mycket känslor, är kunskapen om deras konsekvenser desto mer bristfällig. Vi vet i själva verket väldigt lite om hur framtiden gestaltar sig för de unga som bekänner sig till en ungdomskultur. Påverkas vuxenlivet alls, och om så är fallet, på vilket sätt?

Varje tid har haft sina egna ungdomskul- 
turer och vissa har blivit mer omtalade än andra. Här skall det handla om modsen, en ungdomskultur som skrämde sin föräldrageneration som få andra gjort och som i efterhand blivit mytomspunnen. Vi skall presentera analyser från en stor longitudinell studie där vi kan följa dem som under sin ungdomstid var mods och se hur livet senare kom att gestalta sig för dem. Utifrån de konkurrerande syner på ungdomskulturer som beskrevs ovan kan frågan formuleras som om modsen blev samhällets olycksbarn alternativt dess kreatörer? Det finns också en tredje, mindre dramatiskt möjlighet, nämligen att ingen tydlig effekt alls kan utläsas av tillhörigheten. Kanske kom de flesta mods som vuxna att, likt den generation mot vilka de gjorde uppror, leva "Svenssonliv"?

I denna artikel jämför vi modsen med deras jämnåriga. Hur kom vuxenlivet att gestalta sig? Först skall vi dock se lite närmare på modskulturen och vuxengenerationens reaktioner på den.

\section{Vilka var modsen?}

Modsen blev riksbekanta genom de bråk som utbröt på Hötorget i Stockholm lördagen den 28 augusti 1965. Oroligheterna, som pågick i tio dagar, kom av press och allmänhet att benämnas "modskravallerna». Modsen hade under ett par månaders tid samlats i Hötorgscity. Under slutet av sommaren tillkom även andra ungdomsgrupper, och efter en tids spänningar kom situationen till en urladdning. Den mediala bevakningen var omfattande och kvällstidningarna producerade svarta löpsedlar och åtskilliga spaltmetrar om de tygellösa ungdomarna (se t.ex. Nilmander \& Ahlborn 1998).

Redan innan kravallerna ebbat ut beslutade Stockholms stads barnavårdsnämnd att göra en undersökning av de ungdomar som gripits av polisen. ${ }^{1}$ Syftet med undersökningen var att »dels ge en beskrivning av kravallungdomarna i fråga om bakgrundsdata-sociala förhållanden, familjesituation m.m. - dels en beskrivning av ungdomarnas grupptillhörighet, intresseriktning m.m" (Stadskollegiet 1967, s. 14). Uppgifterna hämtades från register och intervjuer med ungdomarna och deras föräldrar. Denna undersökning utgör än idag den mest omfattande kartläggningen av de ungdomar som kallade sig mods.

Resultaten av kartläggningen visar att de av polisen omhändertagna oftare kom från Södermalm och söderort, fler än normalt var kända av barnavårdsnämnden, färre än normalt bodde med båda föräldrar. En fråga till ungdomarna handlade om grupptillhörighet. En majoritet svarade att de hörde till en ungdomsgrupp. Ungefär en fjärdedel av flickorna och var sjunde pojke svarade att de hörde till modsen. Andra grupper var beatnik, snobb, päron (vanliga ungdomar), sune/doris, raggare och skinnknutte/spätta. Modsen var yngre än de övriga. Av de 61 pojkar som räknade sig som mods var tre av fyra i åldern 13-16 år. Inga tydliga skillnader fanns i socialgruppstillhörighet mellan de

1 Undersökningen omfattade alla ungdomar i åldrarna upp till 21 år som greps under tiden 28 augusti -6 september. Sammanlagt rör det sig om 460 ungdomar, till övervägande del pojkar (Stadskollegiet 1967). 
olika grupperna, modsen kom dock oftare från splittrade familjer. Skillnaderna mellan grupperna sett till vanor och intressen var små. "Naturligtvis kan man finna sådana $\mathrm{i}$ sammanhanget föga originella avvikelser, som att mods lyssnar till musik (pop) mer än sunarna och att sunarna är mer motorintresserade än modsen, liksom att mods i större utsträckning än övriga grupper nämner pop-program bland omtyckta TVprogram. Men för övrigt tycks vanor och intressen - eller bristen på intressen - vara ungefär desamma" (Stadskollegiet 1967, s. 48).

Utredningen beskrev vidare Citymodsen på följande sätt:

"Ungdomarna var uppskattningsvis $i$ aildrarna 12-18 år. Ofta tillbringade de hela dagarna och ibland kvällarna med att sittande eller liggande på Konserthustrappan eller höghusens terrasser lyssna på medförda radioapparater och förtära mat och dryck av skilda slag, bland annat öl $i$ inte obetydlig mängd... Vid vissa tillfällen uppskattades antalet mods enbart $i$ Hötorgscity till ca 500. Dessa stora skaror av ofta uppseendeväckande klädda pojkar och flickor vid Stockholms största köpcentrum väckte irritation hos både allmänheten och affärsidkarna $i$ området. Även ungdomarnas beteende väckte irritation och indignation." (Stadskollegiet 1967, s. 8).

Modskulturen var internationell, men tog sig olika uttryck i olika länder. Enligt ungdomsforskaren Erling Bjurström (1980) begränsade sig likheterna mellan de engelska modsen och de svenska till intresset för den nya brittiska popvågen, med band som
Kinks, Yardbirds, the Who, Pretty Things och Small Faces. Utseendemässigt var de svenska modsen som regel långhåriga. Klädattributen varierade över tid men uppvikta jeans, basketskor med tuschklotter, manchester- och mockajackor, vida parkas samt diverse ringar, arm- och halsband är exempel på några troliga ingredienser i en modsgarderob (se Nilmander \& Ahlborn 1998).

De svenska modsen har i efterhand beskrivits i skiftande termer: Som kommersiell ungdomskultur med en viss musikstil och vissa klädstilar, som proteströrelse med udden riktad mot det mogna industrisamhällets baksidor och som ungdomsproblem och grogrund för kriminell verksamhet och drogmissbruk (se t.ex. Bjurström 1980). Även om alla dessa beskrivningar var och en för sig förmodligen är förenklade, pekar variationen mot att modskulturen aldrig var en homogen rörelse. Bjurström (1980, 1997) menar också att modskulturen påverkades av samhällets tilltagande kommersialiseringen och att den gradvis övergick från proteströrelse till musik- och modeindustri. När det gäller attityder av mer politisk/ samhällelig karaktär brukar ändå en skeptisk hållning till "Svenssonlivet« framhållas som ett förenande element. "Knegarnas» liv ansågs inrutat, bakbundet och fantasilöst vuxengenerationen var full av "losers" vars arbetsliv såväl som fritid var innehållslöst och saknade mening (Bjurström 1980, Nilmander \& Ahlborn 1998).

Modsen var inte bara samtida med en tilltagande kommersialisering av samhället, utan också med narkotikaproblemets etablering i Sverige. Av de problembilder som omgett modsen är antagligen också 
narkotikan den tydligaste. Detta hänger delvis samman med Stefan Jarls dokumentära modstrilogi, där flera av de personer som följs hamnar i tungt missbruk. Vad gäller bruk av droger inom modskulturen är det svårt, för att inte säga omöjligt att säga något om utbredningen. Nilmander och Ahlborn (1998) menar dock att bruket av hasch och amfetamin ("uppåtpiller") fick spridning redan under modsvågens första år, men de poängterar samtidigt att långt ifrån alla använde droger och att många av dem som gjorde det begränsade bruket till helgerna. $^{2}$

Under åren 1968 och 1969 slutade de yngre av "originalmodsen" grundskolan medan de äldre gick mot myndighetsåldern. Nilmander och Ahlborn (1998, s. 24-25) menar att modsen nu stod inför tre huvudval: „Att fortsätta låta håret växa och bli kallad hippie, att ansluta sig till vänstern och åtminstone bli Vietnamaktivist, eller att gradvis dra sig ur, klippa sig allt kortare och köpa en lodenrock, för att nu välja en symbol så god som någon för att ungdomen var över«. Författarna ställer sig också frågan vad som hände med modsen när de blev stora och konstaterar att "[ $\mathrm{t}] \mathrm{ill}$ dess att någon kan betala SCB för en nationell studie kan man bara gissa. Blev de alla misfits eller finns det rent av gamla mods i regeringen?" (Nilmander \& Ahlborn 1998, s. 25). Även om vi genom tillgängliga data inte kan svara på frågan om regeringsmedlemskap, kan vi studera en hel del andra aspekter av modsens vuxenliv. Blev modsen

2 Bruket av amfetamin har även beskrivits som utbrett bland de samtida engelska modsen (Hebdidge 1976). samhällets olycksbarn, dess kreatörer eller blev de flesta av dem Svenssons (med eller utan lodenrock)?

\section{Data-Stockholm Birth Cohort Study}

Stockholm Birth Cohort Study (SBC) är en longitudinell databas som skapats genom en sammanslagning av två avidentifierade datamaterial (Stenberg \& Vågerö 2006, Stenberg et al. 2006). Det första av dessa utgörs av den s.k. Metropolitundersökningen, som består av alla individer födda 1953 och bosatta i Storstockholm tio år senare (Jansson 1995). I Metropolit finns en mängd register- och surveydata, avseende såväl föräldrarna som individerna själva.

Under nästintill hela perioden som projektet pågick (i huvudsak 1963-1983) inhämtades information från olika register. Uppgifter finns om bl. a. inkomster, socialbidragstagande, socialgrupp, betyg, utbildningsnivå, sjukhusvård, ingripanden från barnavårdsnämnden och brottsbelastning. Våren 1966, när kohortmedlemmarna gick i sjätte klass, genomfördes en skolundersökning i form av två enkäter som bland annat behandlade frågor kring vänskap, attityder till skolan och framtidsplaner. Våren 1968 genomfördes en familjeundersökning där mödrar till ett urval av kohortmedlemmarna intervjuades om bland annat yrke, utbildning, syn på uppfostran och sonens/ dotterns utbildningsplaner (SOFI 2005a).

Det andra datamaterialet, med vilken uppgifterna om 53:orna i Metropolit har sammanlänkats, är den s.k. Hälsa, Sjukdom, Inkomst och Arbete databasen (HSIA). 
Denna består av registerinformation om alla individer boende i Sverige 1980 eller 1990. Information finns om bland annat inkomster, yrke och socialbidragstagande.

Då båda databaserna är avidentifierade (Metropolit avidentifierades 1985) har en sannolikhetsmatchning genomförts. ${ }^{3}$ Totalt kunde 96 procent av observationerna 14294 individer - matchas (Stenberg et al. 2006). Genom sammanslagningen av datamaterialen kan de som föddes 1953 och bodde i Storstockholm då de var 10 år gamla följas fram till 48 års ålder.

\section{Operationalisering - vem hörde till modsen?}

Frågan om mods ingår i Familjeundersök-

3 Sannolikhetsmatchning innebär att man för de individer som ingår urskiljt unika kombinationer av de variabler som finns med i båda datamaterialen (för en mer detaljerad beskrivning, se Stenberg et al. 2006). Initiativtagare till och ansvariga för SBC är Denny Vågerö vid Centre for Health Equity Studies (CHESS) och StenÅke Stenberg vid Institutet för social forskning (SOFI). ningen. Det är alltså inte kohortmedlemmarna själva utan deras mammor (i ett fåtal fall pappor) som besvarat frågan. Frågan lyder: Tillhör Er dotter/son de s.k. modsen eller har hon/han gjort det? Svarsalternativen var "Nej", " Ja, har gjort " respektive » Ja, tillhör nu«. Att modsen är den enda ungdomsgrupp som frågas efter kan ses som ett tecken på att den vid tidpunkten var uppmärksammad och oroade.

Hur tillförlitlig är då mammornas bedömning? Att det rör sig om en uppmärksammad ungdomsgrupp gör att vi kan känna oss mer säkra på deras bedömning. Samtidigt finns självfallet ett visst mått av osäkerhet. Social önskvärdhet kan ha inneburit en viss underskattning, det rörde sig trots allt om en ungdomsgrupp förknippad med problem.

Familjeundersökningen gick ut till ett stratifierat urval av kohortmedlemmarnas mödrar. Stratifieringen gjordes efter de poäng kohortmedlemmarna fått i de test på verbal, spatial och numerisk förmåga vilka ingick i skolundersökningen som gjordes två år tidigare. Urvalsförfarandet innebar ett överurval av de fem procent med högst respektive de fem procent med lägst test-

Tabell I.

Tillhör Er dotter/son de s. k. modsen eller har hon/han gjort det?

\begin{tabular}{l|c|c}
\hline \multicolumn{1}{c|}{ Svarsalternativ } & $\begin{array}{c}\text { Metropolit } \\
\text { (t.o.m.30 års ålder) }\end{array}$ & $\begin{array}{c}\text { SBC } \\
\text { (t.o.m. 48 års ålder) }\end{array}$ \\
\hline Nej & 3239 & 3087 \\
Ja, har tillhört & 209 & 200 \\
Ja, tillhörnu & 173 & 167 \\
\hline $\mathrm{N}$ & 3621 & 3454 \\
\hline
\end{tabular}


poäng. Totalt deltog 3651 i underökningen. Det externa bortfallet uppgick till nio procent (Jansson 1980).

Sex procent har tillhört modsen och fem procent tillhör gruppen. Vi har valt att fokusera på dem som tillhör modsen. Vi menar att tillhörigheten till gruppen rimligen inte är långvarig och ej heller stark för den som lämnat den redan före 15 års ålder. Det är 173 personer som var mods då de var 15 år gamla. Bland modsen finner vi fler pojkar (60 procent) än flickor (40 procent). Flertalet av modsen, 167 personer, kan vi genom sannolikhetsmatchningen följa fram till 48 års ålder.

I det följande kommer vi att jämföra modsen med övriga ungdomar. Vi har valt att göra enkla jämförelser mellan modsen och övriga jämnåriga. I de fall vi påtalar skillnader mellan dessa grupper så är de signifikanta (har prövats med hjälp av $\mathrm{Chi}^{2}$ test.) De resultat som presenteras löpande i text redovisas även i tabellform i Appendix (Tabell 4-7).

Till att börja med ställer vi frågan vilka modsen var? Jämförelser görs av socialgrupp, förekomst av ekonomiska problem och familjeförhållanden under uppväxttiden. Fick de som blev mods en sämre start i livet än sina jämnåriga?

I ett andra analysavsnitt jämförs inställningen till skolan och synen på framtiden hos modsen och övriga ungdomar. Finns tecken på en högre "revoltbenägenhet", i bemärkelsen att inte vilja bli en Svensson, hos modsen eller förhåller de sig till skolan och framtiden på ett liknande sätt som sina jämnåriga? Det tredje analysavsnittet behandlar frågor om narkotika och kriminalitet. Skiljer sig dessa faktorer åt mellan modsen och övriga ungdomar? I det fjärde resultatavsnittet presenteras analyser där vi följer individerna fram till 48 års ålder. Här undersöks eventuella skillnader i familjesituation, arbetsmarknadsanknytning och socialbidragstagande mellan de som i ungdomen var mods och de som inte var det. I det femte och avslutande analysavsnittet kombineras så de viktigaste resultaten i syfte att ge ett sammanfattande svar på huruvida modsen blev samhällets olycksbarn, dess kreatörer eller Svenssons. Sist följer några avslutande reflektioner.

\section{Uppväxtvillkor - klassbakgrund, ekonomi och familjeförhållanden}

Klasstillhörighet har mätts med socialgruppstillhörighet 1963, alltså det år då modsen och deras jämnåriga fyllde 10 år. Klassificeringen är i första hand gjord utifrån faderns yrke. ${ }^{4}$ Av Tabell 2 framgår att en större andel av modsen kom från lägre socialgrupp. Var fjärde (25\%) hörde till kategorin icke yrkesutbildade arbetare jämfört med 15 procent bland övriga. Var tionde kom från över- eller övre medelklass, vilket är hälften så stor andel som hos övriga ungdomar. De engelska modsen har beskrivits som utpräglad arbetarklass. Även om det finns skillnader i klasstillhörighet i den riktningen även bland

4 Om personen enbart bor med modern så baseras uppgiften på hennes yrke. Moderns yrke är även bestämmande i de fall där hennes socialgruppstillhörighet är högre än faderns (SOFI 2005b). 
de svenska modsen så hade de alltså sin bakgrund i såväl arbetar- som medelklass.

Det finns också vissa skillnader vad gäller ekonomisk utsatthet i familjen under uppväxten, $i$ det att en något större andel av modsens familjer någon gång haft socialbidrag - 25 procent jämfört med 16 procent bland övriga (Tabell 4). ${ }^{5}$ När vi ser till familjesituation så bodde 15 procent av modsen med en ensamstående förälder då de var 11 år, bland övriga var denna andel nio procent (Tabell 4). ${ }^{6}$

Vi har även en mer direkt indikator på förekomst av sociala problem i uppväxtfamiljen. Denna gäller om personen någon gång under uppväxten, fram till 12 års ålder (år 1965), varit föremål för beslut i barnavårdsnämnden p.g.a. familjeförhållanden. Det gäller tolv procent av modsen och åtta procent av övriga (Tabell 4).

Sammanfattningsvis kommer alltså modsen i större utsträckning än andra från lägre social klass och från mer resurssvaga familjer. Skillnaderna är inte påfallande stora men ändå, i de flesta fall, signifikanta.

5 Gäller perioden 1953-1965. Uppgifterna är hämtade från Socialregistret (SOFI 2005b).

6 Uppgift från Mantals- och inkomstlängden för 1964 (SOFI 2005b).
I de analyser som följer har gruppen övriga standardiserats med avseende på kön och klassbakgrund. Vi har alltså skapat en jämförelsegrupp som har samma fördelning på klassbakgrund och kön som modsen. De skillnader vi kan se mellan mods och övriga kan alltså inte hänföras till skillnader i klassbakgrund eller kön. ${ }^{?}$

\section{Skola och syn på framtiden}

Vad gäller skolgång har vi studerat tre aspekter, hämtade dels från Skolundersökningen, dels från register. Finns någon skillnad mellan modsungdomarna och jämförelsegruppen vad gäller attityder till skolan samt vad gäller skolprestation? Kan vi t.ex. skönja »revoltbenägenhet» gentemot skolan bland modsen? Den första frågan gäller attityd till skolarbetet och lyder: Hur många ämnen i skolan tråkar ut dig? Modsen tenderar att vara något mer uttråkade av skolämnena än sina jämnåriga. Nästan vart fjärde mods anger att alla eller nästan alla

7 Medelvärdet av vikterna är ett, antalet observationer påverkas alltså inte.

Tabell 2.

Socialgruppstillhörighet. Klassificering utifrån faderns yrke 1963. Procent.

\begin{tabular}{l|c|c}
\hline & Mods & Övriga \\
\hline Över- och övre medelklass & 10 & 18 \\
Lägre medelklass & 39 & 40 \\
Arbetare,yrkesutbildade & 19 & 21 \\
Arbetare, ej yrkesutbildade & 25 & 15 \\
Ejklassificerade & 7 & 6 \\
\hline $\mathrm{N}$ & 173 & 3227 \\
\hline
\end{tabular}


ämnen tråkar ut dem, jämfört med 15 procent $\mathrm{i}$ jämförelsegruppen (Tabell 5).

Även den andra frågan mäter attityd till skolarbete. Den lyder: Har du stannat hemma från skolan fast du inte var sjuk? En viss skillnad mellan modsen och övriga finns även här: 41 procent av modsungdomarna uppger att de uteblivit från skolan fast de inte varit sjuka, medan motsvarande andel i jämförelsegruppen är 30 procent (Tabell 5).

Om modsungdomarna alltså visar en något mer negativ inställning till skolan än övriga ungdomar, så kan nästa fråga bli om detta även avspeglas i skolprestation? Avgångsbetyg från årskurs 9 finns tillgängliga från register och en analys av dessa visar att modsungdomarna har lägre betygsgenomsnitt, deras medelbetyg var 2.9 jämfört med jämförelsegruppens 3.2. Sammanfattningsvis skiljer sig modsungdomarnas såväl attityder som prestationer i relation till skolan från jämförelsegruppens på ett sätt som kan tolkas som missanpassning eller kanske som en viss »revoltbenägenhet».

Frågan är nu om det också finns skillnader i sättet att se på framtiden? Har modsungdomarna andra förväntningar på vuxenlivet än jämförelsegruppen och finns det skillnader i hur positivt man ser på framtiden? Vad gäller det förstnämnda ställdes följande fråga: Vad tror du är det viktigaste för att du skall trivas och ha det bra när du blir vuxen? Det fanns sju svarsalternativ: 1) ett bra arbete, 2) att uträtta något, 3) att få göra som jag vill, 4) att ha goda vänner, 5) att ha saker som jag vill ha, t.ex. en bil eller en båt, 6) att vara lyckligt gift, samt 7) annat. Det vanligaste svaret bland såväl modsen som övriga ungdomar är att man helst vill bli lyckligt gift - 46 procent av modsen och 48 procent i jämförelsegruppen har svarat detta. Även fördelningen på övriga svarsalternativ är likartad i de båda grupperna - 36 procent (mods) respektive 35 procent (övriga) har angett att ett bra jobb är de viktigaste, medan åtta procent respektive tio procent valt alternativet goda vänner. Andelarna som svarat något annat understiger genomgående fyra procent (redovisas ej i tabell). Den »revoltbenägenhet« i förhållande till skolan vi möjligen kunde skönja tycks alltså inte gälla drömmarna om det kommande vuxenlivet.

Slutligen i detta avsnitt ser vi till graden av framtidsoptimism som mäts med frågan: Om du jämför dina framtidsutsikter med de flesta andras i din ålder, tror du då att dina är sämre, lika bra eller bättre? Det visar sig här att modsungdomarna ser något mindre ljust på sin framtid än övriga ungdomar: 17 procent av modsen ser sina framtidsutsikter som sämre än andra i deras ålder, jämfört med tio procent $\mathrm{i}$ jämförelsegruppen (Tabell 5).

\section{Sociala problem - narkotika och brottslighet}

I metropolitundersökningen finns tre olika uppgifter om förekomst av narkotikamissbruk: Anteckning i Socialregistret (Barnavårdsnämnd), Slutenvårdsregistret eller förekomst i Stickmärkesundersökning på Kronobergshäktet i Stockholm (Torstensson 1987). Det rör sig här i regel inte om indikatorer på lättare och mer tillfällig användning av narkotika utan ett mer problematiskt missbruk. Uppgifterna täcker perioden fram till 1983, d.v.s. det år undersökningspersonerna fyllde 30 år. 
Vi kan se att narkotikamissbruk var betydligt mer utbrett bland modsen (Tabell 3). Av demsomvarmodsvid tidpunktenförFamiljeundersökningen har 14 procent ett dokumenterat narkotikamissbruk. Bland övriga ungdomar är det ungefär fyra procent, med hänsyn tagen till skillnader i fördelningen på kön och klass. Flertalet av de mods som har missbrukat narkotika har uppgift om det redan i Socialregistret, som täcker perioden fram till dess att de är 19 år gamla. ${ }^{8}$

Vad gäller brottslighet har vi haft tillgång till uppgifter om lagföringar fram t.o.m. 1978, d.v.s. när undersökningspersonerna fyllde 25 år. Även här finns skillnader till modsens nackdel: Andelen av modsungdomarna som lagförts för brott uppgår till 29 procent, att jämföras med 20 procent i jämförelsegruppen (Tabell 5). Då vi ser till

8 Uppgifter finns inhämtade t.o.m. första halvåret 1972. Det kan vara värt att notera att det rör sig om få fall: det är nio av modsen som har registrering om "narkotikabruk i ringa omfattning" och åtta om "omfattande narkotikabruk». Ytterligare ett par har uppgift om narkotikaförseelse, d.v.s. innehav av narkotika. En tredjedel av dem med notering om narkotikabruk i Socialregistret återkommer i Stickmärkesundersökningen och/eller Slutenvårdsregistret. sociala problem som narkotikabruk och brottslighet bekräftas alltså till viss del den hotfulla bilden. Hur detta skall tolkas, om ungdomskulturen är en inkörsport till sociala problem, återkommer vi till längre fram.

\section{Modsen möter medelåldern - sysselsättning, yrke och inkomst}

Vi såg tidigare att modsens framtidsdrömmar inte skiljde sig från övriga ungdomars - att bli lyckligt gift och att ha ett bra arbete var vad man framför allt hoppades på av vuxenlivet. Samtidigt har vi sett att modsen $i$ genomsnitt hade en något mindre positiv attityd till skolan och något lägre avgångsbetyg från årskurs nio. I tidig vuxen ålder hade en större andel av modsen dokumenterat narkotikamissbruk och de var i större utsträckning än jämförelsegruppen lagförda för brott. Hur såg då livet ut för de forna modsen när de kommit upp i medelåldern? Hade den större förekomsten av sociala problem gjort dem till samhällets olycksbarn eller blev modsen senare de Svenssons de trots allt tycktes drömma om att bli? I detta avsnitt analyseras de nya

\section{Tabell 3.}

Förekomst av narkotikamissbruk. Procent (n). Jämförelsegruppen viktad för kön och klass.

\begin{tabular}{l|c|c}
\hline & Mods & Jämförelsegrupp \\
\hline Uppgift om narkotikabruk & $14(24) * * * *$ & $4(146)$ \\
Socialregistret & $10(17) * * * *$ & $3(88)$ \\
Slutenvårdsregistret & $5(8) * * *$ & $2(57)$ \\
Stickmärkesundersökn. & $4(7) * *$ & $2(71)$ \\
\hline $\mathrm{N}$ & 173 & 3449 \\
\hline *** $p<0.05$ **** $p<0.01$ &
\end{tabular}


data genom vilka modsungdomarna kan följas fram till 48 års ålder. Vi studerar här utbildningsnivå, yrkesgrupp, försörjning och familjeförhållanden. Utbildningsnivå har delats in i fyra kategorier: 1) förgymnasial, 2) gymnasial, 3) eftergymnasial kortare än tre år, samt 4) eftergymnasial minst tre år. Resultaten visar på en svag tendens till lägre utbildningsnivå i modsgruppen 16 procent har eftergymnasial utbildning minst tre år jämfört med 21 procent i jämförelsegruppen (Tabell 6).

För att besvara frågan om modsen i högre utsträckning än andra blev samhällets kreatörer, har vi jämfört fördelningen på olika yrkesgrupper bland modsen och i jämförelsegruppen. Det skall sägas att gängse klassificeringsscheman över yrken överlag är mindre lämpade när det gäller att identifiera just sådana verksamheter, då det är troligt att de kreativa verksamheterna för en del är bisysslor som ej tas fasta på i klassificeringen. Vår analys tyder hursomhelst inte på att modsen i högre utsträckning än jämförelsegruppen skulle ha kreativa verksamheter som sin huvudsakliga inkomstkälla. ${ }^{9}$

Hur ser det då ut vad gäller förankring på arbetsmarknaden då undersökningspersonerna är 48 år gamla? Om vi grovt särskiljer dem som år 2001 hade en inkomst av arbete på minst två basbelopp (motsvarar 74000 kronor) från dem som antingen hade låga eller inga inkomster eller förtidspension, finner vi att 82 procent av dem som tillhört

9 År 1990, d.v.s. det år de personer som ingår i undersökningen blev 37 år gamla, hade bara ett av de 147 mods för vilka vi har uppgift »litterärt eller konstnärligt yrke» (enligt den yrkesklassificering som ingår i Folk och Bostadsräkningen 1990). modsen jämfört med 85 procent av övriga hade arbete. Omvänt hade 18 respektive 15 procent en svag arbetsmarknadsanknytning alternativt stod helt utanför. ${ }^{10}$ Skillnaderna är med andra ord mycket små. På samma sätt som vi fann färre högutbildade bland modsen finner vi dock en mindre andel höginkomsttagare bland modsen (Tabell 6). Flertalet har en förankring på arbetsmarknaden, i det avseendet blev modsen, liksom sina jämnåriga, Svenssons.

Men olycksbarnen då? Ett mer direkt mått på ekonomiska problem är förekomst av socialbidrag. Här finner vi en signifikant skillnad mellan mods och övriga: 18 procent av modsen hör till hushåll som under minst ett av fem år (1997-2001) haft socialbidrag, jämfört med elva procent $\mathrm{i}$ jämförelsegruppen.

När det gäller familjeförhållanden slutligen, så finner vi inga tydliga skillnader mellan modsen och deras jämnåriga. Flertalet är vid 48 års ålder sambo eller gifta, de flesta av dem med hemmaboende barn. Andelen ensamstående utan hemmavarande barn är ungefär 30 procent i båda grupperna (Tabell 6).

Vi har ovan konstaterat att narkotikamissbruk förekom mer bland modsen än i jämförelsegruppen. I vilken mån kan detta förklara de skillnader i försörjning som konstaterats ovan? Av Figur 1 framgår att skillnaden i förankring på arbetsmarknaden mellan grupperna hänger samman med den större förekomsten av narkotikamissbruk bland modsen. För dem som haft ett

10 Vi har här valt samma operationalisering som använts i en studie av "unga utanför», d.v.s. unga med svag arbetsmarknadsanknytning (Bäckman \& Nilsson 2007). 
känt narkotikamissbruk blev framtiden mindre ljus och detta oavsett om man kallat sig mods eller inte. Få har försörjning via arbete och det är också många av dem som har avlidit. Bilden ser i själva verket särskilt mörk ut för dem med känt missbruk som inte var mods. Denna skillnad har dock mindre att göra med någon skyddande aspekt av modstillhörighet utan hänger troligen snarare samman med att det är fler i den gruppen som har ett tyngre missbruk, det är exempelvis en större andel av dem som återfinns i Stickmärkesundersökningen. Vi vill också påtala att gruppen narkotikamissbrukande mods är liten, det rör sig här endast om 23 personer.

Samma mönster får vi om vi relaterar socialbidragstagande till dokumenterat narkotikamissbruk (Figur 2), d.v.s. även här kan skillnaden mellan modsen och övriga hänföras till den större andelen mods med narkotikamissbruk. Bland dem med missbruksproblem är andelen socialbidragstagare runt 50 procent i båda grupper, jämfört med cirka tio procent bland dem utan dokumenterat missbruk.

\section{Farligt att vara mods? - kompletterande analyser, sammanfattning och slutsats}

Efter att ha presenterat ett flertal analyser av olika faktorer och från olika tidpunkter ska vi nu sammanfatta dem utifrån frågeställningen hur farligt det egentligen var att vara mods? Vi har sett att när det gäller försörjning i medelåldern så är skillnaderna mellan mods och övriga små. Den grupp det gick sämre för, "samhällets olycksbarn", finner vi bland dem med narkotikamiss- bruk. Det överlag något sämre utfallet för modsen kunde kopplas till en större andel missbrukare i denna grupp. Men var att tillhöra modsen en ingång till missbruk eller delar de mods som registrerats för missbruk snarare bakgrund med övriga som har ett drogmissbruk?

I avsnittet om uppväxtvillkor tidigare analyserades bl. a. andelen bland mods och övriga där barnavårdsnämnden varit inkopplad p. g. a. familjeförhållanden upp till dess att undersökningspersonerna var tolv år. I Figur 3 visas resultatet av en analys där dessa data kombineras med dem om dokumenterat narkotikamissbruk vid 30 års ålder. Notera alltså att uppgifterna om barnavårdsnämnden gäller en period som med största sannolikhet föregår eventuell tillhörighet till modskulturen, och att insatser från nämnden alltså inte kan ses som en konsekvens av det senare. Av figuren framgår ett tydligt samband mellan ingripanden från barnavårdsnämnden och senare narkotikamissbruk. Sambandet är vidare lika starkt i båda grupperna, d.v.s. tillhörighet till modskulturen tycks inte ha någon avgörande roll för sambandets styrka. En liknande bild fås då vi ser till förekomst av socialbidrag i uppväxtfamiljen (Tabell 7).

Slutsatsen av denna studie blir därför att i den mån modsen kom att bli samhällets olycksbarn, så grundlades deras problem redan under tidig uppväxt, genom att de i något högre utsträckning än andra barn växte upp under svårartade familjeförhållanden. Den större förekomsten av sociala problem i uppväxtfamiljen kan kanske ha gjort dessa unga mer benägna att söka sig till en ungdomskultur, men att kalla sig mods verkar inte i sig ha bidragit till en mer 
Figur I.

Arbetsmarknadsstatus vid 48 års ålder samt andel avlidna bland mods och i jämförelsegruppen, efter förekomst av registrerat narkotikamissbruk. Procent.

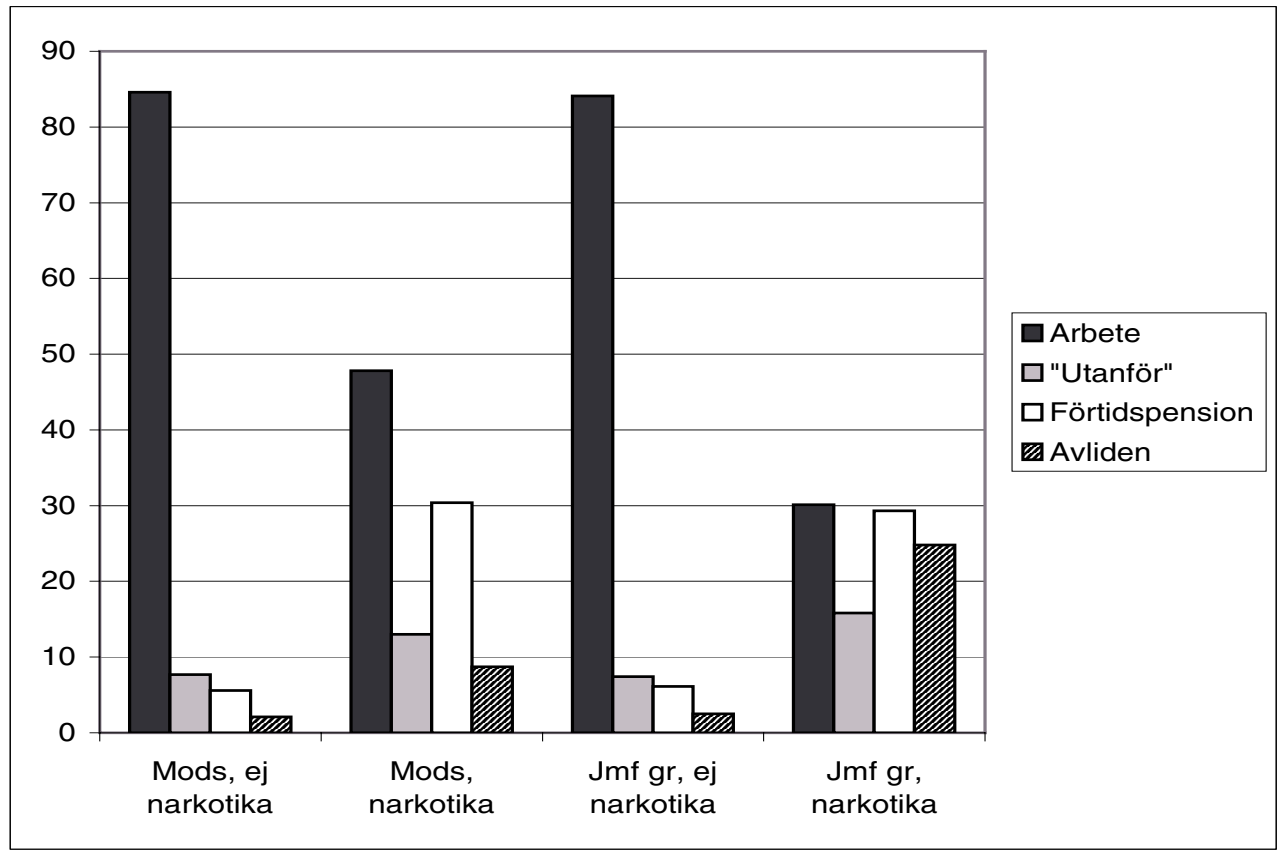

\section{Figur 2.}

Socialbidragstagande bland mods och $i$ jämförelsegruppen, efter förekomst av registrerat narkotikamissbruk. Procent

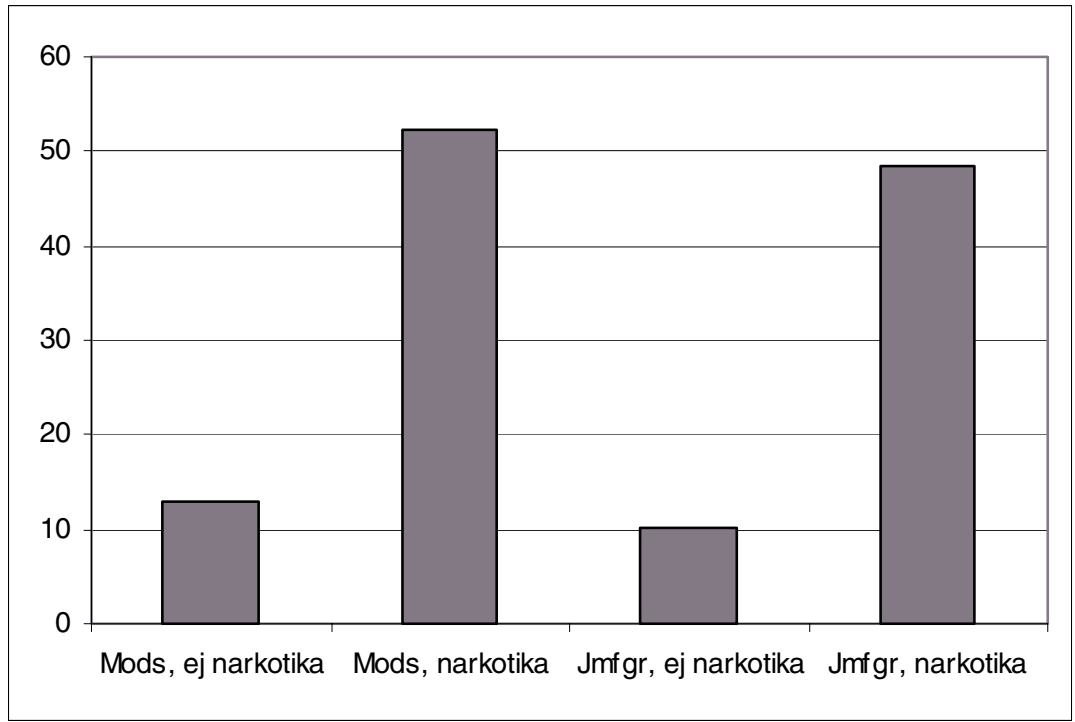

Susanne Alm \& Anders Nilsson: Samhällets olycksbarn, kreatörer eller Svenssons? 
utsatt situation i vuxen ålder. Ungdomar som växte upp under liknande svåra förhållanden, men som inte bekände sig till modskulturen, fick i samma utsträckning som de forna modsen problem med narkotikamissbruk och kriminalitet i vuxen ålder. Och narkotikamissbruk har i denna studie inte oväntat visat sig vara det största hotet mot en trygg situation som vuxen.

Ett sätt att uttrycka studiens slutsats är att tala om betydelsen om det sociala arvet. John Clarke et al. ger i boken Resistance through Rituals uttryck för just en sådan syn:

"Members of a sub-culture may walk, talk, act, look 'different' from their parents and from some of theirpeers: but they belong to the same families, go to the same schools, work at much the same jobs, live down the same 'mean streets' as their peers and parents /.../
Through dress, activities, leisure pursuits and life style, they may project a different cultural response or 'solution' to the problems post for them by their material and social class position and experience. But the membership of a sub-culture cannot protect them from the determining matrix of experiences and conditions which shape the life of the class as a whole"(Clarke et al. 1976, s. 14-15).

De menar att tillhörighet till en ungdomskultur knappast har samma djupgående inverkan på en individ som dennes uppväxtvillkor och att det därmed finns anledning att avdramatisera bilden av ungdomskulturernas skadliga inverkan. Våra resultat menar vi ger stöd för en sådan tolkning.

Den här artikeln har handlat om 1960-talets mods. Modskulturen är inte den första och inte heller den senaste ungdoms-

\section{Figur 3.}

Ärenden i Barnavårdsnämnden upp till 12 års ålder bland mods och övriga, efter förekomst av registrerat narkotikamissbruk vid 30 års ålder. Procent.

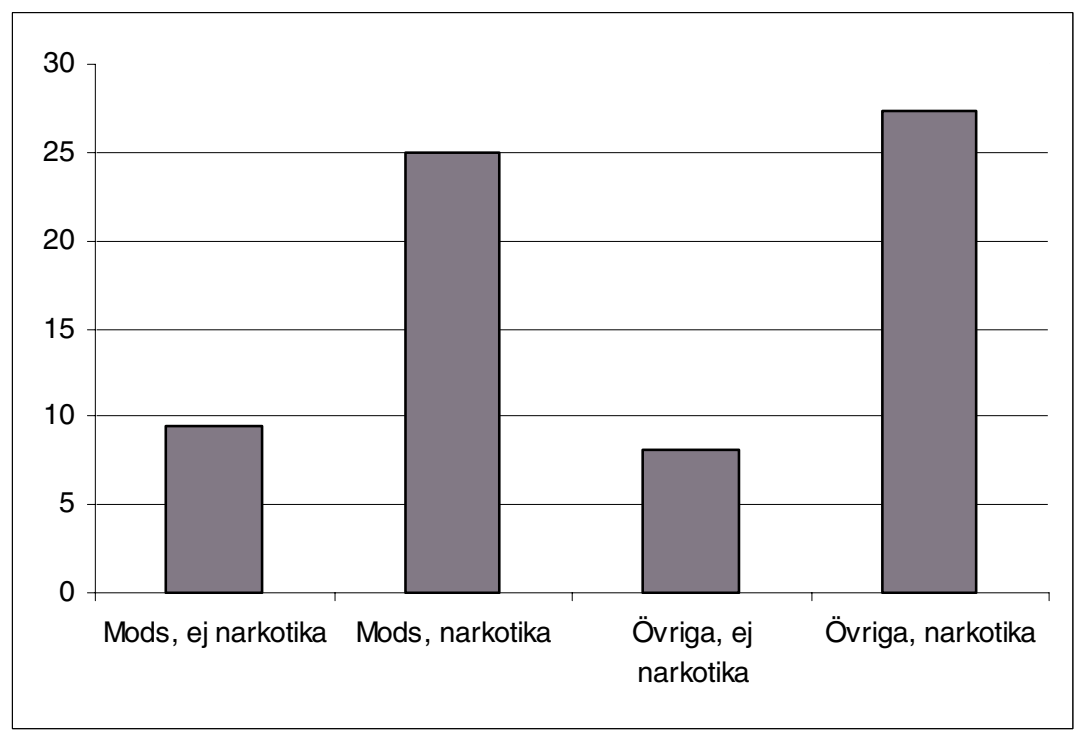


kultur som av vuxenvärlden utmålats som hotfull. Efter dem har vi bl.a. sett det sena 1970-talets punkare och 1990-talets ravare. Gemensamt med modsen är att de anammat en stil som står i kontrast mot de etablerade vuxnas bild av hur ungdomar bör se ut och uppföra sig. Dessa kulturer har också det gemensamt att de framställts som en inkörsport till drogmissbruk (Lalander \& Johans- son 1999). Kanske är Emos dagens motsvarighet till modsen? Även här finner vi vuxna varningar om självdestruktiva inslag. Kanske kan denna studie bidra till att avdramatisera bilden av den skadliga ungdomskulturen, och istället flytta fokus till de bakomliggande förhållanden och uppväxtvillkor som delas av "samhällets olycksbarn".

\section{Referens}

Bjurström, Erling (1980) Generationsupproret. Ungdomskulturer, ungdomsrörelser och tonårsmarknad frän 50-tal till 80-tal. Stockholm: Wahlström och Widstrand.

Bjurström, Erling (1997) Högt och lågt. Smak och stil i ungdomskulturen. Umeå: Borea.

Brill, Dunja (2006) Subversion or Stereotype? The Gothic Subculture as a Case Study of Gendered Identities and Representations. Giessen: UlmeMini-Verlag.

Bäckman, Olof \& Nilsson, Anders (2007) „Ung och utanför - vad innebär det på lång sikt? Arbetsmarknadsanknytning för stockholmare födda på 1950-, 1960- och 1970-talen«. I Jonas Olofsson \& Anna Thoursie Ungas framtidsvägar. Möligheter och utmaningar. Stockholm: Agora.

Clarke John, Hall Stuart, Jefferson Tony, \& Roberts Brian (1976) "Subcultures, cultures and class." IStuart Hall \& Tony Jefferson (1976) Resistance through rituals. Youth subcultures in post-war Britain. New York: Routledge.

Dannefjord, Per \& Eriksson, Magnus (2007) Punk, klass och karriär. Paper presenterat vid Sociologförbundets årsmöte i Lund 2007.

Hebdidge, Dick (1976) »The meaning of mod». I Stuart Hall \& Tony Jefferson Resistance through rituals. Youth subcultures in post-war Britain. New York: Routledge.

Jansson, Carl-Gunnar (1980) The Family Study. Code book. Project Metropolitan, research report no 4. Stockholm: Sociologiska Institutionen, Stockholms Universitet.

Jansson, Carl-Gunnar (1995) On Project Metropoli- tan and the Longitudinal Perspective. Project Metropolitan, research report no 40. Stockholm: Sociologiska Institutionen, Stockholms Universitet.

Lalander, Philip \& Johansson, Thomas (1999) Ungdomsgrupper i teori och praktik. Lund: Studentlitteratur.

Nilmander, Urban \& Ahlborn, Kenneth (1998) Mods. Stockholm 1964-1967. Stockholm: Ordfront/Galago.

Ohlsson, Lars B \& Swärd, Hans (1994) Ungdom som samhällsproblem. Lund: Studentlitteratur.

SOFI (2005a) Project Metropolitan - Codebook I. Stockholm: Institutet för social forskning.

SOFI (2005b) Project Metropolitan - Codebook II. Stockholm: Institutet för social forskning.

Stadskollegiet (1967) Hötorgskravallerna i Stockholm hösten 1965. Stadskollegietsutlåtanden och memorial, nr. 93, bihang. Stockholm: Stadskollegiet.

Stenberg, Sten-Åke \& Vågerö, Denny (2005) "Cohort Profile: The Stockholm birth cohort of 1953", International Journal of Epidemiology, vol 35, s. 546-548.

Stenberg Sten-Åke, Vågerö Denny, Österman Reidar, Arvidsson Emma, von Otter Cecilia \& Jansson Carl-Gunnar (2005) „Stockholm Birth Cohort Study 1953-2003: A new tool for lifecourse studies", Scandinavian Journal of Public Health, vol 35, s. 104-110.

Torstensson, Marie (1987) Drug-Abusers in a Metropolitan Cohort. Project Metropolitan, research report no 25. Stockholm: Sociologiska institutionen, Stockholms Universitet.

Susanne Alm \& Anders Nilsson: Samhällets olycksbarn, kreatörer eller Svenssons? 


\section{Summary}

\section{Social outcasts, free creators or mainstream citizens? The future of the Swedish mods in retrospect}

Who were the Swedish Mods and how did their adult lives develop as compared with that of others in their generation? Did the mods become the social outcasts, the free creators of society or, less dramatically, mainstream citizens? Unique data from the Swedish Birth Cohort Study (SBC) allow for a longitudinal follow-up of individuals identifying with the Swedish mod culture in the late 1960s.

The results point in the least dramatic direction - the vast majority of individuals identifying with the mod culture in their teens tends to live ordinary adult lives with work and family. However, some differences were found. Most importantly, drug abuse was more common among the former mods. Analyses of childhood conditions indicate that this can be explained by a larger pre- valence of social problems in the family of origin. In other words, social problems in the family of origin may have increased the incentive to join a youth culture like the mods. Likewise, social problems in the family of origin, rather than identification with the mod culture per se, are likely to be the primary explanation for the somewhat larger prevalence of drug abuse among the former mods.

Although the results should be generalised with caution, the study could at least serve as an argument against expressions of moral panic over the consequences of teenage identification with youth cultures. The study suggests that structures that give some children a disadvantaged start in life are a better focus for concern. 


\section{Appendix: Tabell 4-7}

Tabell 4.

Uppväxtvillkor bland mods och övriga. Procent (n).

\begin{tabular}{llc}
\hline & Mods & Övriga \\
\hline Uppväxtvillkor & & \\
\hline Socialbidrag (1953-1965) & $24,9(43) * * *$ & $16,0(550)$ \\
Barnavårdsnämnd p.g.a. familjeförhållanden & & \\
(1953-1965) & $11,6(20) *$ & $7,8(268)$ \\
Ensamstående förälder (1964) & $15,0(26) * *$ & $9,4(323)$ \\
\hline
\end{tabular}

\section{Tabell 5.}

Skola, syn på framtiden och sociala problem. Procent (n). Jämförelsegruppen standardiserad för klassbakgrund och kön.

\begin{tabular}{|c|c|c|}
\hline & Mods & Jämförelsegrupp \\
\hline \multicolumn{3}{|l|}{ Skola och syn på framtiden } \\
\hline »Hur många ämnen i skolan tråkar ut dig?« (1966) & *** & \\
\hline Alla eller nästan alla & $23,3 \quad(37)$ & $14,7 \quad(479)$ \\
\hline Ungefär hälften & $27,7 \quad(44)$ & $16,6 \quad(539)$ \\
\hline Några få eller inga & $49,1 \quad(78)$ & $68,7(2232)$ \\
\hline $\begin{array}{l}\text { »Har du stannat hemma från skolan fast du inte var } \\
\text { sjuk?«(1966) }\end{array}$ & **⿻丷木大 & \\
\hline Nej & $59,4 \quad(98)$ & $69,8 \quad(2249)$ \\
\hline Ja, någon gång & $35,5 \quad(55)$ & $26,7 \quad(860)$ \\
\hline Ja, flera gånger & $5,2 \quad(8)$ & $3,5 \quad(113)$ \\
\hline Medelbetyg årskurs 9 & $2,91(172) * * * *$ & $3,15(3407)$ \\
\hline $\begin{array}{l}\text { »Om du jämför dina framtidsutsikter med de flesta } \\
\text { andras i din ålder, tror du då att dina är sämre, bättre } \\
\text { eller lika bra?« (1966) }\end{array}$ & *** & \\
\hline Sämre & $16,8 \quad(26)$ & $10,0 \quad(319)$ \\
\hline Lika bra & $67,7 \quad(105)$ & 69,7 (2227) \\
\hline Bättre & $15,5 \quad(24)$ & $20,3 \quad(649)$ \\
\hline \multicolumn{3}{|l|}{ Sociala problem } \\
\hline Lagförd för brott (t.o.m. 1978) & $29,5 \quad(51) * * *$ & $20,4 \quad(702)$ \\
\hline
\end{tabular}

Susanne Alm \& Anders Nilsson: Samhällets olycksbarn, kreatörer eller Svenssons? 


\section{Tabell 6.}

Familj, utbildning, sysselsättning och inkomst vid medelåldern. Procent (n). Jämförelsegruppen standardiserad för klassbakgrund och kön.

\begin{tabular}{|c|c|c|}
\hline & Mods & Jämförelsegrupp \\
\hline \multicolumn{3}{|c|}{ Familj, utbildning, sysselsättning och inkomst } \\
\hline Familjetyp (200I) & Ej sign. & \\
\hline Sambo/gift & $6,2(10)$ & $10,2(319)$ \\
\hline Sambo hemmaboende barn & $49,7 \quad(80)$ & $48,5(1495)$ \\
\hline Ensamstående med barn & $13,7 \quad(22)$ & $11,7 \quad(360)$ \\
\hline Ensamstående & 30,4 (49) & 29,5 (909) \\
\hline Utbildningsnivå (2000) & Ej sign & \\
\hline Förgymnasial & $25,5(4 I)$ & $20,2(625)$ \\
\hline Gymnasial & $40,4 \quad(65)$ & $43,5(1346)$ \\
\hline Eftergymnasial<3 år & $18,0 \quad(29)$ & $14,8(458)$ \\
\hline Eftergymnasial>3 år & $\mid 6,1 \quad(26)$ & $21,5 \quad(667)$ \\
\hline Socialbidrag ( $1997-200$ I) & $18,0(29) * *$ & $11,4 \quad(352)$ \\
\hline Inkomstgrupp (200 I) & Ej sign & \\
\hline Låginkomsttagare (20\% lägst) & $22,4 \quad(36)$ & $20,0 \quad(618)$ \\
\hline Medelinkomsttagare & $62,1(100)$ & $57,9(1786)$ \\
\hline Höginkomsttagare (20\% högst) & $15,5 \quad(25)$ & $22,0 \quad(680)$ \\
\hline
\end{tabular}

Tabell 7.

Socialbidrag under uppväxttiden (1953-1965) bland mods och övriga efter förekomst av narkotikamissbruk. Procent.

\begin{tabular}{ccccc}
\hline Socialbidrag & $\begin{array}{c}\text { Mods, } \\
\text { ej nark }\end{array}$ & $\begin{array}{c}\text { Mods, } \\
\text { nark }\end{array}$ & $\begin{array}{c}\text { Övriga, } \\
\text { ej nark }\end{array}$ & $\begin{array}{c}\text { Övriga, } \\
\text { nark }\end{array}$ \\
\hline $\mathrm{Nej}$ & 77,9 & 58,3 & 84,7 & 65,3 \\
$\mathrm{Ja}$ & 22,1 & 41,7 & 15,3 & 34,7 \\
\hline $\mathrm{N}$ & 149 & 24 & 3324 & 124 \\
\hline
\end{tabular}

